Masuma H. Mammadova, Zarifa G. Jabrayilova

DOI: 10.25045/jpit.v09.i1.02

Institute of Information Technology of ANAS, Baku, Azerbaijan

depart15@iit.ab.az

\title{
TECHNIQUES FOR PERSONNEL SELECTION IN VIRTUAL ORGANIZATION
}

The article presents the types and features of virtual organizations and the characteristic features of human resource management. Human resources management in virtual organizations is characterized as a matter of decision-making in a fuzzy environment. Based on the peer comparison of expert estimates for the alternatives, including on the hierarchical analysis method, detection of the contradictions in the expert estimates and multiplicative aggregation methods, a decision making technique is proposed for the recruitment of the employees. The empirical experiment of the recruitment issue based on the proposed technique is described.

Keywords: virtual organization, human resource management, selection of employees, hierarchical analysis method, multiplicative aggregation.

\section{Introduction}

The massive expansion of Internet technologies at the end of the twentieth century has led to the formation and substantial enhancement of the virtual environment in the employment sector: virtual companies, virtual corporations, virtual divisions, and the range of virtual businesses have expanded. The process of virtualization of organizations resulted with a change in social-labor relations and traditional governance mechanisms in the labor sphere, and has changed the staffing functions, signing the labor contracts and their content, and the traditional institutions for the data collection. Thus, the age of formation of new type companies, based on knowledge, intellect and innovation, has launched. The most obvious example is the emergence of virtual organizations (VO) $[1,2]$.

The information about so-called virtual corporation (VO) was first appeared in the early 1990s by Steven L. Goldman, Rocer N. Nagel, and David B. Greenberger, and William H. Davidow and Michael S. Malone [3-5].It is noted that,[2,3] in order to achieve a common goal, the company has to use its both internal and external partner relationships to mobilize more activists than it currently possesses, and hence, the VO is formed. It is shown that [4] the innovative technology market enables the enterprises to form a temporary partnership, and the creation of such links over the Internet results in the formation of the VOs. [5] describes VO as a broader and overarching notion, covering a large number of management ideas and new terms. It is noted that the market requirements often change and separate organizations lack in necessary skills and competences to address these requirements. In this case, VOs are created with the participation of partner companies that meet the requirements $[6,7]$. The relations between VO members usually occur through a computer network; and the managers coordinate and manage foreign affairs through computer network connections. From this point of view, they are flexible organizations. The flexibility entails multiple versions of implementation, flexible work schedule, incomplete working day, job sharing, and freelance work. One of the most important principles here is to respond quickly to both internal and external changes.

At present, VO in the business sector is accepted as a firm that holds the external contractors to fulfill its core functions. In some cases, VOs are created from independent organizations that share resources and skills to achieve the goals. Generally, depending on the degree or spectrum of virtuality, $\mathrm{VO}$ is divided into three categories: remote $\mathrm{VO}$, employee/competence outsourcing organization, and complete VO [8-10].

Currently, VO widely encompasses Internet projects, programming, journalism, trading, and so on. The expansion of VO stems from the following advantages [11-13]:

- allows specialists to save time, travel costs, and ensures availability;

- employees and partners can be remotely arranged; 
- opportunity to use external experts without any preparation and travel expenses;

- dynamic membership allows people to move from one project to another;

- employee may involve at several projects and teams;

- team connections and work can be posted on the Internet that enables to quickly respond to market requirements;

- employees may upload information about their personal and professional lives;

- virtual groups allow companies to expand their potential labor market, enabling them to attract and retain better employees, regardless of their physical location.

One of the most important advantages of VO is working remotely at home [13]. It is claimed that [14], in the United States, 6.1 million people work virtually at home, in a café or other place. This became a normal practice, and was approved that the performance is higher than in traditional organizations. The top 50 companies in this area include Dell, American Express, Xerox, Apple, Humana, IBM, About.com, Microsoft, Thomson Reuters, Mozilla, Bausch \& Lomb, SAP, General Electric, Cisco Systems, Google, JetBlue, Citibank and others.

Thus, VO has some characteristics such as dynamics, non-formal communication, multidisciplinary (virtual) team, uncertain organization borders, goal orientation, freelance work, lack of visible organizational structure, reference to mental work of integrated workers, and so on.

\section{Human resource management issues and their features in VO}

The success of VO depends on its human resources management (HRM). Employee and partner planning, selection, deployment, socialization, motivation and evaluation are dependent on the proper organization of HRM. They are responsible for the management and regulation of the environment to achieve the expected goals $[7,8]$.

The knowledge-based job at VOs requires empowered competences from employees seeking improvement of their living conditions. From a HRM perspective, VO promises good opportunities for both parties. First, researchers are autonomous, independent, and financial stability exists. On the other hand, the factors such as increasing the working hours, avoiding stress arisen from the communication with the external persons and avoiding dismissals have led to increased labor performance [7]. In such organizations, workplaces are short-term and rapidly changing, the accumulation of employees is time-consuming and requires high productivity [15, 16]. All the above-mentioned peculiarities sets out the following requirements for the workforce involved in VO [1]:

- ability to clearly and concisely express the issue (international organizations require foreign language skills);

- writing, electronic communication skills;

- wide scope knowledge, abilities to solve a few issues in parallel;

- set goals and time;

- ability to find non-standard solutions for solving various issues;

- high personal responsibility for the outcome of the work (for which the employee should be familiar with the relevant instructions, the basics of legislation, the company's ethic guidelines);

- have to imagine the work of the organization;

- ability to successfully collaborate in virtual environments (this is related not only to the individual's psychological features, but also to corporate management culture and changing technologies) and so on.

Rewarding and stimulating personnel is crucial for ensuring high productivity at VO. The lack of an independent assessment framework for evaluation of the contributions of the employees provided to the overall corporate goals with the observation of the development trends of advanced information technology, new business ideas and progress creates problems. Thus, the activity of the workforce of VO is "short-term", and the lack of mechanisms to ensure the "short-term" 
stimulation of the personnel and to measure its contributions in achieving the overall objective of the $\mathrm{VO}$, is another issue, the solution of which is a matter of urgency.

Apparently, personnel management at VO requires managers to work in a flexible, innovative environment, non-standard approaches and solutions, and upgrade of the management system with changing issues faced by the organization. From this point of view, the work of managers at $\mathrm{VO}$ can be called innovative, which urges the development of the decision support systems based on intellectual technology.

\section{Modeling the recruitment of the employees at VO}

The main task of VO is to find partners and sign a mutually profitable contract. Choosing and collecting employees or partners and forming innovative teams creates a number of new requirements for employers as follows [17]:

- involvement of employees or professionals who mastered innovative technologies and are ready to work in a more flexible, virtual business environment than the traditional one;

- identification of the characteristics of next generation employees, regardless of the geographical parameters, space and time(reserve formation);

- identification of the methodology for more accurate and flexible communication with the employees;

- adoption and use of new technology priorities.

To establish innovative teams, VO sets out specific and vital requirements for selected employees. The requirements include $[1,17]$ :

- level of intelligence determined by the analytical, abstract, and systematic thinking ability of the employee, "confidence in intellect" in problem solving;

- professionalism, familiarization with the work;

- responsibility and flexibility, knowledge of organizational procedures, effectively communicative and readiness for adaptation;

- $\quad$ ability to work in team and to focus individual goals on achieving overall results.

Thus, the above listed define the following characteristics of human resources management issues at $\mathrm{VO}$ :

- $\quad$ incomplete and inaccurate information possessed by the decision-maker of Vo about the capabilities of the companies, co-workers and partners included into VO and their productivity;

- communication relationships of VO's activity based on trust factor, and consequently, dependence of the outcome of the activity on subjective and psychological aspects;

- dependence of the general corporate outcome on local results and inaccuracy and uncertainty the latter;

- $\quad$ dependence of the results of HRM issues at VO on quantitative and qualitative aspects; the emergence of uncertainties arising from the time factor.

These aspects upload HRM of VO in a "fuzzy" environment, and characterize it as a semistructured and hard to formalize problem. Decision-making in such an environment makes it necessary to use the methods of formalization of expert knowledge as the formalism of incomplete and inaccurate information processing, and the use of fuzzy logic theory [18].

Selection of partners and partners is crucial for the formation of $\mathrm{VO}$, however, very little attention is paid to the decision-making methods in solving this issue. Let's take a brief look at the analysis of several methods devoted to this problem.

[19] focuses on the methodological aspects of the partner selection. In [20] proposes a decision for the selection of suppliers. This model is economically oriented and depends on the co-operation with partners and the computing of transport costs. The goal function implies to minimize the value function; the quality criteria are overlooked. The approaches presented in [21, 
22] are similar, and based on the linear programming, a decision-making method based on mathematical model and criteria is proposed for the problem solution. However, the use of linear programming does not adequately represent the uncertainties and characteristics of the selection problem. [23] reviews the multi-criterion analysis of the problem for enterprise ranking, and refers to some criteria such as, investment, share turnover, sales income per employee, and others. The authors offer to identify the rating of the enterprises by aggregating the criteria, based on the method PROMETHEE, using the hierarchical analysis method (HAM) to determine the importance ratio. [24] uses HAM to determine the power and potential productivity of the partners based on quantitative and qualitative criteria. The HAM is used to find the relative weight of the individual partners in a common purpose. [25] offers a solution to the issue of collective decision making for the selection of suppliers, based on HAM.

The analysis shows that the process of selection of partners should be viewed not as a mathematical modeling issue but as a matter of multi-criteria decision-making. The use of classical HAM in the multi-criteria decision-making issues creates the basis for its use in the selection of the partners. The incompleteness and inaccuracy of the information possessed by the decision-maker about the capabilities and productivity of the partners is reflected in the uncertainty of the relationship of the first ones. The consideration of such uncertainty problem in the assessment confirms of the urgency of the use of HAM and fuzzy numbers obtained by referring to the statements' comparison $[18,26]$. [6, 16] reviews the issue of selecting the partners based on such approach. [6] uses the value, quality, financial stability, customer service as an evaluation criteria, while [16] proposes a method for determining the proximity of the ideal solution based on HRM for a quick and objective choice of partners in solving certain projects. The proposed approach is solved by referring to additive aggregation [27, 28], which enables the participation of any alternative in the recruitment even though it (alternative) is equal to zero, and even allows selecting the best alternative.

Such an approach can be used to hire employees in traditional organizations, and he compensation of the unsatisfied criteria can be attributed to other criteria (or employee's training in organizational activities may be envisaged) [29]. However, in the VO, employees are involved in the implementation of a specific short-term project $[2,15,16]$ for each of these requirements are to be satisfied, and this requires a reference to the multiplicative aggregation method for selecting the best alternative and ranking the alternatives.

On the other hand, it is also crucial to check whether the expert estimates are agreed upon in the decision-making process when referring to the comparison of the expert statements. Hence, in this article, the issue of selecting employees and partners at VO is reduced to the multi-criteria decision issue referring to the comparison of expert statements to evaluate the employees and partners, and to determine HAM and the methods of detecting the contradictions in expert evaluations, and decision-making method is proposed by referring to multiplicative aggregation methods for choosing the best alternative.

\section{Technique for selection of employees at VO}

The technique for the selection of employees at VO is offered in the following stages:

1. formulation of problem, alternatives, criteria and goals;

2. assessment of criterion;

3. determining the importance ratios of criterion;

4. detection of contradictions in the expert statements concerning the assessment of criterion;

5. assessment of alternatives;

6. selection of alternative with the highest value.

HAM-based decision making process has a hierarchical structure that has elements on the levels, and each level has a number of crucial elements (Figure 1):

- upper level of the hierarchy implies the general purpose and is indicated by $R$; 
- next level of the hierarchy implies the criteria and is indicated by $K=\left\{k_{j}, j=\overline{1, m}\right\}$;

- lower level of the hierarchy displays all possible alternatives: $X=\left\{x_{i}, i=\overline{1, n}\right\}$.

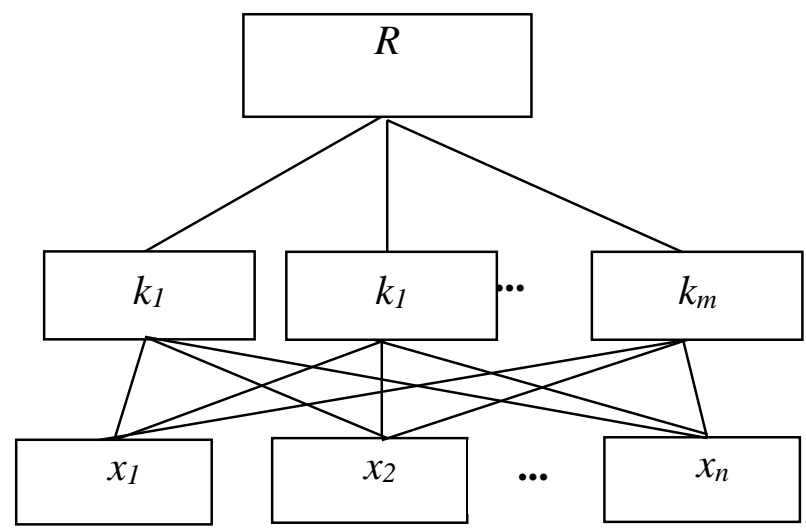

Fig. 1. Hierarchical structure of the selection of employees at VO

The decision-maker (expert) expresses his/her attitude in linguistic values that indicate the peer comparisons of priorities (second level - criteria, and third level - alternatives) for each level. Comparison of the second level of priorities (criteria) defines the weight value of the criteria $w_{j}, j=\overline{1, m}$, and the comparison of the third level of priority (alternatives) defines their fuzzy values $r_{k_{j}}\left(x_{i}\right), i=\overline{1, n}, \quad j=\overline{1, m}$. These values represent the priority of the alternative $x_{i}$ for criteria $k_{j}$. The common purpose values of the alternatives are determined by referring to multiplicative aggregation based on the following formula $[28,30]$ :

$$
R_{i}=\prod_{j=1}^{m} r_{k_{j}}\left(x_{i}\right)^{w_{j}}
$$

Here, $R_{i}, i=\overline{1, n}$ is a fuzzy number used for the ranking and selection of the alternatives and expresses the priority of each alternative for a common purpose.

The main issue when using HAM is a peer comparison of the priorities at the same level and finding a relative importance factor in relation to each other. Decision-making is carried out in the following stages and solved by selecting the best alternative:

- obtaining the statements of the peer comparison of the criteria and establishing peer comparison tables by referring to [26, 31], and determining relative importance ratios $w_{j}, j=\overline{1, m}$;

- detection of contradictions in expert statements;

- peer comparison of the alternatives for each criterion, formation of comparison tables;

- calculation of the priority ratios $R_{i}, i=\overline{1, n}$ of the alternatives based on the formula (1).

- selecting the alternative with the highest value: making decision on selecting a partner and $R^{*}=\max \left\{R_{i}, i=\overline{1, n}\right\}$.

To find the importance ratios of the priorities on the basis of their peer comparisons, 9-grade Saaty schedule is used [26] (Table 1). 
Table 1

9-scale Saaty table of relative priority degrees of criteria

\begin{tabular}{|c|l|}
\hline Value & \multicolumn{1}{|c|}{ Linguistic expression } \\
\hline 1 & Criteria $K_{l}$ does not exceed the criteria $K_{2}$ \\
\hline 3 & Criteria $K_{l}$ fairly exceeds the criteria $K_{2}$ \\
\hline 5 & Criteria $K_{l}$ noticeablyexceeds the criteria $K_{2}$ \\
\hline 7 & Criteria $K_{l}$ significantly exceeds the criteria $K_{2}$ \\
\hline 9 & Criteria $K_{l}$ exceeds the criteria $K_{2}$ several times \\
\hline $2,4,6,8$ & intermediate ideas among listed degrees \\
\hline
\end{tabular}

If the number of indicators is equal to $m$, the relationship matrix is set knowing the relations of number $m-1$ implying their peer comparison, and the matrix has the features of diagonally $\left(K_{j j}=1, j=\overline{1, m}\right)$, symmetry $\left.K_{t j}=K_{j t}{ }^{-1}\right)$ and transitivity $\left(K_{t g} \cdot K_{g j}=K_{t j}\right)$. Importance ratios of the matrix-based criteria are based on the following formula [26, 31]:

$$
w_{t}=\sum_{j=1}^{m} k_{t j} \times\left(\sum_{t=1}^{m} \sum_{j=1}^{m} k_{t j}\right)^{-1}
$$

The maximum specific value of the matrix $\lambda_{\max }$ is calculated based on for verifying that the expert statement is agreed upon the peer comparison of the priorities. For this purpose, it is referred to the method of rough estimation of consistency, and the matrix of comparisons is multiplied to the relative importance ratios of criteria [26]. A further vector is obtained through dividing the first component of the new matrix by the importance of the first criterion, and the second component by the importance of the second criterion, and so forth. $\lambda_{\max }$ (maximum or head-specific value) is obtained by dividing the sum of the components by the number of the components of this vector. The closer the value of $\lambda_{\max }$ to $n$, the more agreed the result is. The deviation from the Consistency index $(C I)$ of the agreement is designated by the formula below as follows:

$$
C I=\left(\lambda_{\max }-m\right) /(m-1)
$$

Diving consistency index of the matrix by the appropriate Random Consistency $(R C)$ limit allows the assignment of Consistency Relation $(C R)$ :

$$
C R=C I / R C \text {. }
$$

According to [26] random consistency $R C=0,58$ for matrix $m=3$; $R C=0,90$ for $m=4$; $R C=1,12$ for $m=5 ; R C=1,24$ for $m=6$, and so forth.

When $C R \leq 0,1$, consistency limit is considered to be acceptable, otherwise, the expert assessment is required to be reviewed again.

\section{Empirical experiment}

We had a brief look at the recruitment of the personnel at VO based on the proposed method. The key problem in the problem solution is the selection of criteria for the evaluation. For this purpose, four criteria, that is evaluation criteria are referred to, which characterize each employee to be recruited at VO and are important to be provided (obligatory requirement) $K=\left\{k_{j}, j=\overline{1,4}\right\}$. Here, $k_{l}$ denotes the level of intelligence, $k_{2}$ - professionalism, $k_{3}$ - responsibility, $k_{4}$ - team work ability.

Alternatives: $X=\left\{x_{i}, i=\overline{1,3}\right\}$ - applicants intention to work at VO.

The goal is to select the best candidate for VO out of three candidates, who provide are all criteria. That is $X^{*}=\max \left\{R_{i}, i=\overline{1,3}\right\}$.

The problem is solved by the following stages. 
Stage 1.Assumethat the results of peer comparison of the criteria for the applicants' evaluation are as follows: $k_{12}=3, k_{13}=5, k_{14}=7, k_{23}=2, k_{24}=4, k_{34}=4$. Based on these expert estimates, the following comparison matrices are set up (Table 2).

Table 2

Peer comparison matrix of the criteria characterizing the applicant to $\mathrm{VO}$

\begin{tabular}{|c|c|c|c|c|}
\hline $\begin{array}{c}\text { Comparison } \\
\text { of criteria }\end{array}$ & $k_{1}$ & $k_{2}$ & $k_{3}$ & $k_{4}$ \\
\hline$k_{1}$ & 1 & 3 & 5 & 7 \\
\hline$k_{2}$ & 0,33 & 1 & 2 & 4 \\
\hline$k_{3}$ & 0,2 & 0,5 & 1 & 4 \\
\hline$k_{4}$ & 0,143 & 0,25 & 0,25 & 1 \\
\hline
\end{tabular}

The relative importance ratios of the criteria for the given table are determined by the formula (2): $w_{1}=0,521, w_{2}=0,239, w_{3}=0,186, w_{4}=0,054$.

The comparison matrix is multiplied by the relative importance ratios to verify that the expert estimates on the peer comparison of the criteria are agreed, and the following vector is obtained:

$$
\left(\begin{array}{llcc}
1 & 3 & 5 & 7 \\
0,33 & 1 & 2 & 4 \\
0,2 & 0,5 & 1 & 4 \\
0,143 & 0,25 & 0,25 & 1
\end{array}\right) \times\left(\begin{array}{l}
0,521 \\
0,239 \\
0,186 \\
0,054
\end{array}\right)=\left(\begin{array}{l}
1 \times 0,521+3 \times 0,239+5 \times 0,186+7 \times 0,054 \\
0,33 \times 0,521+1 \times 0,239+2 \times 0,186+4 \times 0,054 \\
0,2 \times 0,521+0,5 \times 0,239+1 \times 0,186+4 \times 0,054 \\
0,143 \times 0,521+0,25 \times 0,239+0,25 \times 0,186+1 \times 0,054
\end{array}\right)=\left(\begin{array}{l}
2,546 \\
1 \\
0,626 \\
0,236
\end{array}\right)
$$

$\lambda_{\max }$ is determined through dividing the sum of the results, which are obtained from dividing each component of the obtained vector by the importance ratio of the respective criterion, by the number of the criterion:

$$
\begin{aligned}
& \lambda_{\max }=(2,546: 0,521+1: 0,239+0,626: 0,186+0,236: 0,054) / 4= \\
& (4,89+4,18+3,37+4,37) / 4=16,8 / 4=4,2
\end{aligned}
$$

Using the formula (3):

$$
C I=(4,2-4) /(4-1)=0,2 / 3=0,07
$$

is defined. And according to [26], using the formula (4) $C R=0,07 / 0,9=0,08$ is defined, if taking into account that $R C=0,90$ for four-component matrix.

Thus, the condition $C R \leq 0,1$ is provided for the given case, that is, expert estimates are agreed.

Stage 2. Peer comparison of the alternatives is performed according to each criterion. Based on expert statements and Table 1, an appropriate matrix is set. Assume that the comparison of alternatives according to the criteria is as follows.

2.1. The following table is set up in accordance with the expert statement "according to the criteria $k_{l}$, almost all applicants are equal" (Table 3).

Table 3

Peer comparison matrix of applicants for the criteria of intellectuality

\begin{tabular}{|c|c|c|c|}
\hline $\begin{array}{c}\text { Comparison of } \\
\text { alternatives }\end{array}$ & $x_{1}$ & $x_{2}$ & $x_{3}$ \\
\hline$x_{1}$ & 1 & 1 & 1 \\
\hline$x_{2}$ & 1 & 1 & 1 \\
\hline$x_{3}$ & 1 & 1 & 1 \\
\hline
\end{tabular}


The table defines the priority ratio of the alternatives according to the criteria of intellectuality: $r_{11}=0,333, r_{12}=0,333, r_{13}=0,333$.

2.2. According to the criteria of professionalism, the comparison of applicants matrix is set based on the expert estimates " $x_{12}=x_{13}=x_{23}=2$ " (Table 4).

Table 4

Peer comparison matrix of applicants for the criteria of professionalism

\begin{tabular}{|c|c|c|c|}
\hline $\begin{array}{c}\text { Comparison of } \\
\text { alternatives }\end{array}$ & $x_{1}$ & $x_{2}$ & $x_{3}$ \\
\hline$x_{1}$ & 1 & 2 & 2 \\
\hline$x_{2}$ & 0,5 & 1 & 2 \\
\hline$x_{3}$ & 0,5 & 0,5 & 1 \\
\hline
\end{tabular}

Based on the assumptions, $r_{12}=5 / 10,5, r_{22}=3,5 / 10,5, \quad r_{32}=2 / 10,5$.

2.3. According to the criteria of responsibility and flexibility, the comparison of applicants matrix is set based on the expert estimates" $x_{12}=3, x_{13}=5, x_{23}=5$ " (Table 5).

Comparison of applicant matrix for the criteria

Table 5 of responsibility and flexibility

\begin{tabular}{|l|l|l|l|}
\hline Alternatives & $x_{1}$ & $x_{2}$ & $x_{3}$ \\
\hline$x_{1}$ & 1 & 3 & 5 \\
\hline$x_{2}$ & 0,333 & 1 & 5 \\
\hline$x_{3}$ & 0,2 & 0,2 & 1 \\
\hline
\end{tabular}

Based on the assumptions, $r_{13}(x 1)=0,538, r_{23}(x 2)=0,6, r_{33}(x 3)=0,084$.

2.4. According to the criteria of team work ability, the comparison of applicants matrix is set on the basis of expert grading " $x_{12}=x_{13}=5, x_{23}=6$ " (Table 6).

Table 6

Comparison matrix for the criteria of team-work ability of candidate

\begin{tabular}{|c|c|c|c|}
\hline Alternatives & $x_{1}$ & $x_{2}$ & $x_{3}$ \\
\hline$x_{1}$ & 1 & 5 & 8 \\
\hline$x_{2}$ & 0,2 & 1 & 6 \\
\hline$x_{3}$ & 0,125 & 0,167 & 1 \\
\hline
\end{tabular}

Based on the assumptions, $r_{14}=0,622, r_{24}=0,32, r_{34}=0,057$.

Stage 3. The obtained results are given in Table 7.

Table 7

The priorities of the alternatives according to the criteria

\begin{tabular}{|c|c|c|c|c|}
\hline $\begin{array}{c}\text { Criteria and their weight } \\
\text { coefficients }\end{array}$ & $\begin{array}{c}\text { intelligence } \\
w_{1}=0,521 \\
r_{i 1}\end{array}$ & $\begin{array}{c}\text { proficiency } \\
w_{2}=0,239 \\
r_{i 2}\end{array}$ & $\begin{array}{c}\text { responsibility } \\
\text { and flexibility } \\
w_{3}=0,186 \\
r_{i 3}\end{array}$ & $\begin{array}{c}\text { Team work ability } \\
w_{4}=0,054 \\
r_{i 4}\end{array}$ \\
\hline$x_{1}$ & 0,3333 & 0,476 & 0,538 & 0,622 \\
\hline$x_{2}$ & 0,3333 & 0,333 & 0,6 & 0,32 \\
\hline$x_{3}$ & 0,3333 & 0,016 & 0,084 & 0,057 \\
\hline
\end{tabular}


Using the results provided in Table 7 and the formula (1), the values of the common purpose coefficient priority of the alternatives are calculated.

$$
\begin{aligned}
& R_{1}=\prod_{j=1}^{4} r_{k j}\left(x_{1}\right)^{w_{j}}=0,333^{0,521} \times 0,476^{0,239} \times 0,538^{0,186} \times 0,622^{0,054}=0,564 \times 0,837 \times 0,891 \times 0,975=0,41 . \\
& R_{2}=\prod_{j=1}^{4} r_{k j}\left(x_{2}\right)^{w j}=0,333^{0,521} \times 0,333^{0,239} \times 0,6^{0,186} \times 0,32^{0,054}=0,564 \times 0,769 \times 0,909 \times 0,94=0,371 . \\
& R_{3}=\prod_{j=1}^{4} r_{k j}\left(x_{3}\right)^{w j}=0,333^{0,521} \times 0,016^{0,239} \times 0,084^{0,186} \times 0,057^{0,054}=0,564 \times 0,372 \times 0,631 \times 0,857=0,113 .
\end{aligned}
$$

Stage 4. The alternative with the highest value and ranking are defined:

$$
\begin{gathered}
R^{*}=\max \left\{R_{i}, i=\overline{1, n}\right\}=\max \left\{R_{1} ; R_{2} ; R_{3}\right\}=R_{1} . \\
R_{1}>R_{2}>R_{3} .
\end{gathered}
$$

Thus, decision made on choosing the alternative $x_{1}$ as the best alternative for $\mathrm{VO}$ is the best solution.

\section{Conclusion}

The proposed approach allows VT to take into account the ambiguity, incompleteness of criteria for the selection of employees (partners), to formalize expert evaluations, to verify their compliance, and to select the best decision that meets all the alternatives. The proposed approach is aimed at ensuring the most adequate decisions made to select employees at VO.

The proposed approach can be used for the solution of other multi-criteria issues, where each of the requirements (criteria) to the alternatives must be provided.

\section{References}

1. Sankova L. HR-management in virtual organizations: problems and prospects // Personnel management, 2007, No5. www.top-personal.ru/issue.html?1043

2. Camarinha-Matos L. M. Afsarmanesh H. Designing the information technology subsystem, in Handbook on Enterprise Architecture, P. Bernus, L. Nemes, G. Schmidt (Eds.), Springer, 2003.

3. Hopland J. Virtual Organization and Dynamic Business Structures. In: Organisationsforum Wirtschaftskongress e. V. (Hrsg.): Mehrwert Information. Kommunikationsformen, Markte und Arbeitsweisen in der Informationsgesellschaft. Stuttgart, 1995, pp.173-190.

4. Goldman S.L., Nagel R.N. Agile Competitors and Virtual Organizations: Strategies for Enriching the Customer Kenneth Preiss http://eu.wiley.com/WileyCDA/WileyTitle/productCd-0471286508.html

5. Davidow W.H., Malone M.S. The Virtual Corporation: Structuring and Revitalizing the Corporation for the 21st Century. New York, NY: Harper Collins Publishers, 1992.

6. Mikhailov L. Fuzzy analytical approach to partnership selection in formation of virtual enterprises // Omega, vol. 30, is.5, 2002, pp.393-401.

7. Heneman R.L., Greenberger D.B. Human resource Management in virtual organization, Information age publishing, 2002, $381 \mathrm{p}$.

8. Junyan DU. Information Technology in Virtual Enterprise Human Resources Management Application. www.seiofbluemountain.com/upload/product/201010/2010qychzh03a3.pdf

9. Chand S. What is Virtual Organisation? Definition, Characteristics and Types. www.yourarticlelibrary.com/organization/what-is-virtual-organisation-definitioncharacteristics-and-types/35533/

10. Nami M.R. Virtual Organization: An Overview // In book: Intelligent Information Processing 
IV, 2008, pp.211-219. DOI:10.1007/978-0-387-87685-6_26.

11. Ulrich D., Beatty R.W. The Role of the HR Professional in the Virtual Organization file:///C:/Users/HP/Downloads/HR\%20in\%20Virtual\%20Organizations\%20beatty\%20ulrich.pdf

12. Advantages and disadvantages of virtual enterprises. www.managertip.ru/tubvs-239-1.html

13. Vozza S. How a company works when $100 \%$ of the staff is virtual, Fast Company, May 20, 2015. www.fastcompany.com/3046333/the-new-rules-of-work/how-a-company-works-when-100of-the-staff-is-virtual, entry taken on November 15, 2015.

14. Lepore M. 50 of the Best Companies Hiring Remote Workers, October 30th, 2014, available on http://skillcrush.com/2014/10/30/50-companies-hiring-remote/

15. Samdantsoodol A., Cang S., Yu, H., Eardley A., Buyantsogt A. Predicting the relationships between virtual enterprises and agility in supply chains // Expert systems with applications, 2017, vol.84, no.10, pp.58-73. DOI: 10.1016/j.eswa.2017.04.037

16. Polyantchikov I., Shevtshenko E. Karaulova T., et.al. Virtual enterprise formation in the context of a sustainable partner network // Industrial management \& data systems, 2017, vol.117, no.7, pp.1446-1468.

17. Boljanovic J. D., Dobrijevic G., Dokovic F. Challenges of human resource management in a virtual business environment / Sinteza, International Scientific Conference on ICT and EBusiness Related Research, 2016, pp.389-394.

18. Zadeh L.A. The concept of a linguistic variable and its application to the adoption of approximate solutions, M .: Mir, 1976, $168 \mathrm{p}$.

19. Meade L., Liles D, Sarkis J. Justifying strategic alliances and partnering: a prerequisite for virtual enterprising // Omega, 1997, vol.25, pp.29-42.

20. Kaslingam R., Lee C. Selection of vendors-a mixed integer programming approach // Computers and Industrial Engineering, 1996, vol.31, pp. 347-350.

21. Talluri S., Baker R, Sarkis J. A framework for designing eLcient value chain networks // International Journal on Production Economics, 1999, vol.62, pp.133-144.

22. Dean B., Schniederjans M. A multiple objective selection methodology for strategic industry selection analysis // IEEE Transactions on Engineering Management, 1991, vol.38, pp.53-62.

23. Babic Z., Plazibat N. Ranking of enterprises based on multicriteria analysis // International Journal on Production Economics, 1998, vol.56-57, pp.29-35.

24. Ossadnik W. AHP-based synergy allocation to partners in a merger // European Journal of Operational Research, 1996, vol.88, pp. 42-49.

25. Maggie C.Y.Tam, Rao Tummala V.M. An application of the AHP in vendor selection of a telecommunications system // Omega, 2001, vol.29, no.2, pp.171-182.

26. Saati T.L. Decision-making. Hierarchical analysis method. M.: Radio and Communication, 1993, $320 \mathrm{p}$.

27. Larichev O.I. Theory and methods of decision making, and chronicle of events in magical countries: A Textbook. M.: Logos, 2002, 392 p.

28. Neuman D.V., Morgenstern O. Game theory and economic behavior. M .: Science 1970, 708 c.

29. Mammadova M. H., Jabrayilova Z. G. , Methodological approach to multi-criteria decisionmaking in the management of human resources // Information Technologies, 2016, No6, pp.467-480

30. Mamedova M.G., Jabrailova Z.Q., Mammadzada F.R. Fuzzy Multi-scenario Approach to Decision-Making Support in Human Resource Management. In book: L.A. Zadeh et al. (eds.),Recent Developments and New Direction in Soft-Computing Foundations and Applications, Studies in Fuzziness and Soft Computing, Springer International Publishing Switzerland 2016, vol.342, pp.19-36. DOI 10.1007/978-3-319-32229-2_3

31. Mammadova M.H., Djabrailova Z.G., Nobari S.M. Use of information about the importance of the criteria in the solution of personnel management problems / The second International Conference "Problems of Cybernetics and Informatics" PCI-2010, Baku, pp.83-86. 